\title{
Stylistic Analysis of an Extract from Purple Hibiscus
}

\author{
Minzi $\mathrm{Li}^{1^{*}}$ Ligerui Chen ${ }^{2}$ Yongqiang Zeng ${ }^{3}$ \\ 1. Guangdong University of Foreign Studies, Baiyun Dadao Bei \#2, Guangzhou, Guangdong, 510420 \\ China \\ 2. Queensland University of Technology, Brisbane, Queensland, QLD 4000, Australia \\ 3. Guangdong Teachers College of Foreign Language and Arts, Tianhe Shougouling \#463, Guangzhou, \\ Guangdong, 510640 China \\ *E-mail of the corresponding author: whlmz@163.com
}

\begin{abstract}
This study attempts to carry out an in-depth stylistic analysis of an extract from Purple Hibiscus by Chichamanda Ngozi Adichie to demonstrate how a detailed stylistic analysis can reveal the ways in which the different linguistic features can be manipulated to achieve a wide range of significant effects. Salient linguistic features in the construction of meaning and frameworks fruitful in the discussion of the particular extract based on a close reading of the literature are employed for approaching the stylistic analysis. The study examines, in particular, the linguistic control of viewpoint, speech and thought presentation as well as how readers are invited to get into central characters' head throughout the extract, which give insights into the narrator's external perception of the particular event in the fictional world. Furthermore, close attention is paid to the interpersonal function of language in the analysis of the conversational part of the extract. Methods of discourse analysis in terms of body language, turntaking mechanism, co-operation, politeness and the character are applied to investigate the linguistic strategies and patterns indicated in the dialogue. Findings demonstrate the personalities of characters, their tense relationship, and the struggle for the dominance of power in the interaction. Moreover, the alternative world is applied to further probe how the concept of different worlds of the characters in the textual universe can be used to describe the conflicts which start the plot of the novel and internal structure of the fictional worlds. Based on findings, general conclusions and implications for future studies are revealed.
\end{abstract}

Keywords: stylistic analysis, point of view, mind style, speech and thought presentation, conversational analysis, alternative worlds

DOI: $10.7176 /$ JLLL/68-07

Publication date:May $31^{\text {st }} 2020$

\section{Introduction}

Much work in stylistics involves an extensive analysis of extract or individual literary texts (Semino, 2004). By relating specific linguistic choices and patterns to potential meanings and effects, invaluable insights into the texts and language as well as useful hypotheses and explanations regarding readers' interpretations are demonstrated (Semino, 2004). This study intends to perform a stylistic analysis of an extract from the Purple Hibiscus by Chichamanda Ngozi Adichie. The novel is set in postcolonial Igbo region of eastern Nigeria where people endure a turbulent time of political strife and economic difficulties. The story is narrated from the first-person perspective by Kambili Achike, a 15-year-old Nigerian girl growing up in sheltered privilege in a country ravaged by political instability and personal struggle.

The extract is taken from the beginning of the novel ranging from p. 45-p.48. There are two main characters in the extract: Kambili Achike, I-narrator of the story, a shy and inhibited 15-year-old girl, who has a conflicting feeling of both adoration and fear towards her father; and Eugene Achike (the father of Kambili), a religious zealot and violent character in the Achike household. He wears two masks when facing the public and his "loved ones" (i.e., family members). He is a benevolent and compassionate businessman receiving recognition from the local people as many citizens have received his blessings and material assistance. However, as a religious fanatic, he controls every aspect of his family's life, holds "zero tolerance" to mistakes and imposes a harsh religious regime to his family members, leaving family members full of emotional wounds and mental trauma.

In the extract, father imposes a schedule upon the lives of Kambili and her brother and mapped out every minute of the day for them. Kambili only ranked second in the previous term exam, which frustrates her father most since he always set a high expectation for his daughter. On the first day of the new semester, the father, therefore, takes Kambili to school and even humiliates her in front of schoolmates regardless her feelings on the matter. $\mathrm{He}$ 
interrogates her rudely why she wouldn't rank the first in the school performance and force her to make an invalid promise which is not in the power of Kambili to fulfil it (in terms of speech act theory). Even confronted with the direct face-threatening acts and endless blames, the girl tries not to offend the negative face of the father.

This study will approach the extract in a stylistic framework in order to contribute to a more concrete interpretation of its meaning and the effects that the text may have upon its potential readers. First, it begins by presenting a summary of the story considering the fact that background information about the plot and the characters will set the scene for a stylistics analysis. Then it introduces the main characters and how readers are invited to get into central characters' head while considering issues of point of view and speech and thought presentation. Furthermore, a detailed account of conversational analysis will be explored in terms of body language, turn-takings, power relations, politeness, co-operation and character before moving on to issues of plot development to show how the concept of alternative worlds of the characters in the textual universe can be used to describe the conflicts which prompt the plot of the novel. General conclusions and implications for future studies will be revealed in the end. A modified copy of the text with numbered sentences will be provided in the appendix for easy reference.

\section{Kambili's Point of view and Mind style}

\subsection{Point of View}

A crucially important key aspect of a stylistic analysis of a novel is the examination of the point of view, namely the angel from which the events that take place in the fictional world are demonstrated (Fowler, 1986;1996). In the extract, events are told from the point of view of Kambili, a timid 15-year-old protagonist, which the main character of the story is also I-narrator (Toolan, 1995; Short,1996). The novel is told in the past tense and events are developed in chronological order as if Kambili is looking back past events and telling the story directly to readers. The discourse structure (Short, 1996, pp.256), hence, can be considered rather straightforward that goes directly from the narrator to the readers, helping slant readers towards the "particular" fictional world (Leech \& Short, 2007). In this regard, readers are persuaded to adopt Kambili's point of view and are likely to sympathise with her position.

According to Fowler (1996), Kambili's viewpoint can be embodied in terms of four levels: spatial, temporal, psychological and ideological point of view. Spatial point of view refers to the place in the fictional world from which things are seen (Fowler, 1996). Deictic expressions in the extract demonstrate the space relating to the Kambili's internal perception. Examples can be seen: "beyond the stretch of manicured lawn", "from the midst of students and... quickly waddled over to us", "got to the front of my class" and "walk down the path". Temporal point of view specifies the impression that time is moving slowly or fast; move forward and back (Fowler, 1996), which is not salient in the extract since I-narration of the story develops in chronologically and presented the in past tense. It should note that though there is only a three-year gap between Kambili as narrator and Kambili as the character, these are years in which people become mature and change dramatically. Psychological point of view provides access to the minds of characters in the story, which can be further categorised into the type A (firstperson or one character) and type B (i.e., third-person or more than one character) (Fowler, 1996). The psychological point of view of the extract falls into Fowler's internal psychological type A, which give readers access to Kambili's mind directly. Examples such as "I wondered what he was doing, why he was here..." and "I hoped my class girls were not wondering why..." manifest Kambili's anxiety and fear (i.e., internal feeling) to her father, which will be further elaborated in the speech and thought presentation. The notion of the ideological point of view is also internal, specifying the view of the world that is assumed in the story, such as attitudes, value judgements or prediction (Fowler, 1996; Simpson, 1993). In the extract, Kambili express her judgements to her father in a rather "direct" manner (Fowler, 1996, p.166-167) through evaluative adjectives and verbs. Evaluative adjectives adopted in "he was gracious, in the eager-to-please way that he..." clearly reveals the traits (i.e., courageous, generous) of the father when he faces the public since he even changes his accent (a typical example of sociolinguistic accommodation) talking to Benedict (the priest) to defer to the social status. Besides, the evaluative verb in "he expects much from you. He expects perfection..." clearly depicts the father as an overbearing and religious zealot from Kambili's voice. Therefore, both internal perceptions Kambili to her father and beliefs/attitudes held by Eugene (Kambili's father) in the fictional word can be easily accessed.

\subsection{Mind Style}

According to Leech and Short (2007), mind style refers to how the fictional world is conceptualised by the mind whose point of view is being demonstrated. This notion is relevant when the narrative point of view is deviant 
from the "normality" (p.151) (i.e., mind styles are exposed to works in an unusual way). However, in our case, the novel falls into the category of "normality" rather than "default", which can be explained by its high compatibility with reality. There are plenty of linguistic indicators in the extract that demonstrate the characters' personality (Fowler, 1977;1986;1996). Bockting (1995) clarifies that vocabulary choices may be considered as the most salient technique for the projection of mind style as an individual's lexical repertoire may reflect their concepts. Leech and short (2007) assert mind style is essentially a matter of semantics and can be observed by grammar. The extract displays a preference to use simple lexical and syntactic patterns, which portray a clear picture of Kambili and her father' characteristics. For example, the father is depicted as a violent, tyrannical figure which can be seen from the short, simple imperatives (e.g., "look in the mirror", "look at her") and direct interrogative questions (e.g. "where is your classroom?", "where is Chinwe Jideze?", "how many heads do you have?"). Another power device for the evocation of mind style, figurative languages (i.e., metaphorical patterns) such as metaphor, personification and parallelism (Lakoff and Turner,2009; Turner and Fauconnier, 2000; Semino and Swindlehurst, 1996; Steen, 1999) are identified in the extract. "her words flew generously out of her mouth" here is a metaphor, suggesting that Sister Margaret talks too much and speaks quickly and thus give us the idea of her character; "feeling a weight around my temple", another metaphor, clearly show us the internal states of Kambili (she feels stressful and get frightened of her father); "how many heads does she have... how many heads do you have?" (parallelism) and "the ground to open up and swallow the whole compound" also hint the anxiety and fear of the girl and her obedience to father.

Moreover, conversational patterns (i.e., linguistics indicators at the pragmatic level), such as the unintentional breaking of Grice's maxims, may also contribute to the presentation of mind styles. Flouting the Grice's maxim of quality (i.e., say something untrue in order to generate an implicature) (Grice, 1975) can be observed in sentences (24), (32) as the father asking Kambili ridiculous known questions of numbers of heads. In sentence (35), Kambili violate Grice's maxim of relevance (i.e., respond her father irrelevant answers) considering she is not trying to make implicature rather than placate her father and escape from his interrogation as quickly as possible. Besides, examples of politeness and impoliteness strategies (Brown and Levinson, 1987) are identified in the extract, such as the bald-on record (sentence 34), not offending father's negative face (sentence 26, 39) and face-threatening acts (e.g., "the girl has one head, too, she does not have two. So why did you let her come first?").

\section{Speech and Thought Presentation}

The speech and thought presentation, another crucially important aspect of narrative, has received increased attention and concern in stylistics and narratology (e.g., Fludernik, 2003, Leech and Short 1981, Toolan 2012). Main forms in which the words or thoughts of characters presented in the narrative are employed in the extract (e.g., direct speech, direct thought, free indirect speech or free indirect thought, etc.). Differences in 'norm' for speech and thought presentation account for some differences in effects between corresponding forms of presentation and thus may display varied effects on the ways readers perceive the plot development and the characters as well as give readers access to the point of view from which the fictional world is depicted.

\subsection{Speech Presentation}

More than two-thirds of the extract is concerned with the conversation between the father and Kambili (i.e., proportions of words of speech presentation), which contributes to reflect the character's perceptions and attitudes. Main categories of speech presentation which cline of interference from the narrator to the character's control are identified and further employed for the stylistic analysis of the extract: (1) Indirect speech (IS) specifies representing an utterance via a reporting clause followed by a reported clause which language used is appropriate to the narrator (i.e., tense and pronouns, lexis, deixis); (2) Free indirect speech (FIS) refers to representing utterances without a reporting clause and using language that is partly appropriate to the narrator (i.e., tense and pronouns) and partly to the character (i.e., lexis, deixis); (3) Direct speech (DS) specifies representing utterances via a reporting clause and a reported clause (typically enclosed in quotation marks) which language adopted in the reported clause appropriate to the speaking character (i.e., tense and pronouns, lexis, deixis) and (4) Free Direct speech (FDS).

In the extract, the frequent forms of speech presentation are DS and FDS, while forms of IS and FIS are lessfrequently used in the extract. Considering words presented by DS are normally a verbal reproduction of the original speaker, DS often deemed to be associated with the "conventional faithfulness claims". To be specific, the character reports speech faithfully to what originally said in the fictional world as it claims to (claims normally include original words, propositions and the speech acts) (Short, 1996). Though conventional association has 
appeared to be problematic in discourse contexts in recent years (e.g., Slembrouck, 1992; Tannen, 2007), however, in the extract, the disbelief of readers (when reading fiction) bring about a high degree of reliability to DS stretches and thus made readers believe the speech reported in DS form was 'actually' uttered by the characters in the fictional world (see Short, et al., 2002). Moreover, the DS, serves as the baseline, normally results in the foregrounding effect of the speech it relates to since it offers us direct impression that readers listen to the characters' voices with no mediating interference of the narrator (Leech and Short, 2007). This effect of DS applies to most instances of DS in the extract (see sentences 2, 13, 20,24, 32 and 41) as all those spoken words are quoted without the narrator's interference and thus bring readers more direct insights into characters.

The less prototypical forms, FDS, should also be taken into consideration. Leech and Short (1981) distinguish the FDS variant from the prototypical form of DS as it captures speech presentation with the absence of the quotation marks or reporting clauses (e.g., sentences $25,28,30,33-35,37,42-44,45)$. Though they mention ambiguity and confusion may generate in the readers' mind without the introductory clause (Leech and Short, 2007), however, this is not the case in the extract considering the limited length of the words. In general, DS forms (including the FDS variant) employed in the extract adds to the effect of immediacy and directness, which allow the characters to speak for themselves and shorten the distance between the readers and the characters. Therefore, readers can easily perceive the personalities and characteristics of the father and the daughter and the sharp contrast in between.

Apart from the DS forms (DS and FDS), sentences (12) and (8) are presented in the IS forms (IS and FIS). According to Leech and Short $(1981 ; 2007)$, IS forms (particularly FIS) are associated with the creation of distancing effects and used for ironic purposes. They further mention that the choice of IS forms normally involves a move from the norm (i.e., DS) towards the narratorial end of speech presentation forms. The example of the sentence (12) gives readers space to perceive the different mask wears by the father (i.e., he acts generously and courteously when facing the local people, which is of sharp contrast when he treats her family members. Sentence (8), functions as a typical demonstration of FIS, displays the strong distancing effect (between readers and Sister Margret) to fulfil its ironic purpose.

\subsection{Thought Presentation}

Besides the externally presented words, thought presentation, presents the flow of thoughts in the characters' mind internally and invites readers to view things from the point of view of the character (Leech and Short, 2007). Thought presentation can sometimes form a counterpoint to speech presentation when the report of conversational exchanges is punctuated by the presentation of the thoughts of characters. These thoughts normally relate to the belief or attitudes that characters cannot express openly and thus likely to contrast with what the characters say (Semino and Short, 2004). Categories of thought representation parallel in form of the speech presentation categories contain direct thought (DT), free indirect thought (FIT), indirect thought (IT), narrator's representation of thought act (NRTA), and narration of internal states/internal narration (NI).

Though the father demonstrates to speak longer and more frequent than the daughter, speech presentation alternates between the two characters in the extract. In contrast, in the reading of the extract, readers are only given direct access to Kambili's thoughts and internal states (see sentences 4, 18, 21, and 39). The extract presents readers the internal states of Kambili by using IS (e.g., sentence 4) since the sentence includes the basic elements of the introductory reporting clause, the subordination and the reported clause, and thus put readers directly into Kambili's mind and to perceive her internal states of anxiety and fear towards the father. Furthermore, FIT (see sentences 18, and 21) is evident in the extract. Here the less vivid and immediate form FIT (the default form of thought presentation) is employed considering it does not carry the potential for artificiality and is typically related to the representation of the content rather than the wording of one's thoughts (Leech and Short,1981; Halliday, et al., 2014). It should note that the story is the first-person narration, the thought of the narrator and that of the main character are blended (Leech and Short, 1981) as Kambili serves both I-narrator and the character at the same time in the novel.

It is interesting to spot that the extract contains instances of ambiguity between two less-direct categories of thought presentation (i.e., IT and NRTA). Sentences (39), a typical demonstration, can either fall into the category of IT or NRTA since the sentence formally has two clause-structure. However, we would argue it be better to categorize into the category of the NRTA (i.e., NRTA primarily refers to a reference to the illocutionary force of speech - a notion that cannot be applied to a non-communicative context straightforwardly such as specific acts of thoughts or silent speech acts) (Semino and Short, 2004). Both the word "hoped" and "wondering" used in the sentence hint what Short (1996) calls "thought presentation embedded in thought presentation". Here schoolmates' internal thinking is imbedded inside Kambili's report of her own hypothetical thought about what her schoolmates may 
think. It should note that readers by far may not fully sure whether her schoolmates are near enough to hear and understand what is going on simply from the extract.

\section{Conversational Analysis}

An utterance stands in a certain structural relationship with the other utterances in a conversation, which denotes interactional meaning (Culpeper and Mclntyre, 2005). Over two-thirds of the extract is composed of a fictional presentation of an interaction between two characters, Kambili and her father, which give readers insights into their personalities and the nature of the relationship. The conversation portrays a clear picture of the daughter's intimidation, embarrassment and the obedience, father's dominance as well as the tension and uncomfortable feelings in between. Conversational analysis will focus aspects of body language, turn-taking mechanism, politeness, co-operation, and character in hope to shed the light for characters.

\subsection{Body Language}

Personalities and internal perceptions can be accessed through the body language of two characters. According to Folwer (1996), body languages (e.g., movements of eyes, postures and facial expressions) are of equal importance as words as, and sometimes may inform readers more detailed information about characters' internal states. In the extract, it's interesting to find that for the first time, the submissive daughter (Kamibili) refuse the command of the father when she is asked to look in the mirror. Instead, she stares at the father with eyes of inquiring wonder, neither saying a single word nor follow the instruction. With no words articulate explicitly, here the body movement "stare" not only indicative Kambili's questioning attitude towards her father but also her silent resistance.

Even Kambili has no reason to follow the order of the father to look at the girl, she does anyway (sentence 26), which presents us the fear and emotional stress the girl sense from her violent father. Such uncomfortable feelings are further enhanced when the father endlessly blames her in front of the public. Readers may access to Kambili' $\mathrm{s}$ internal states through her body movements and facial expressions since the poor girl simply react her father with the cautious head-nodding (sentence 39). Besides, "a brief side hug" to end up the conversation provides readers with a more direct feeling that there is not a loving father-and-daughter relationship. The impression of the father is, thus, sketched as a rigid, overbearing tyrant figure and impose harsh regime to the households, leaving his daughter full of emotional wounds and mental scars.

\subsection{Turn-taking Mechanisms}

The turn-taking mechanisms (e.g., the distribution of talk, turn allocation, turn transition, or topic controls) deals with the switch on roles between interlocutors, which are closely associated with power relations in a conversation (Short, 1996). Performing the analysis of turn-taking mechanisms may reveal us how power is distributed between two characters (i.e., Kambili and her father). In the extract, Kambili exhibits far less power than the father. The inequality power relation, thus, brings varied effects upon the amount of individual speaker's progress of the interaction.

In the extract, two characters share nearly an equal amount of turns, which is a normal case when there are only two participants in the interaction. The father has longer turns in the conversation as he utters at least one or two sentences each time while Kambili only speaks at most 7 words for each turn. The father serves as the leading role in the power distribution. He changes topics and leads the adjacency pairs (i.e., control sequences in conversations). Though Kambili seems very cooperative and submissive throughout the interaction, she tries to balance the power distribution in the conversation as she responds her father with silent resistance (i.e., she simply stares at her father with no words reply) (sentence 29) and even tries to switch the topic (sentence 35) to go against the father. However, Kambili fails to take back the dominance in the dialogue due to the inferior position in households, while the father completely takes control over the conversation. It is interesting to find that with the unfolds of the conversation, different topics introduced by the father always begins with interrogatives and imperatives.

The topic that the father pursues is to compel his daughter to be aware of the serious consequences of letting him down, elicits a positive assurance from his daughter (sentence 34-35), and imposing his belief of in pursuit of perfection upon his daughter (sentence 37). He achieves these by asking obvious questions in the sentence (24) and enhance it in the sentence (32). The daughter, Kambili, on the other hand, only in hope of not being humiliated in the public and not offend the negative face of the father (see sentences 25, 38 and 39). Besides, the skipconnecting pattern is evident in the extract: despite continue discussing the topic proposed by other interlocutors, 
the character is prone to link back to his own topic and skip other's contribution (Broe, 2003). The example can be viewed in sentences (35) and (37). The father here seem to ignore his daughter's commitment when he severely interrogates her why she cannot rank the first among her schoolmates. Instead of a reply to his daughter' promise, he links back to his persuasion and blames previously and kept expressing his endless anger.

\subsection{Politeness}

If an utterance serves one part of the interaction, it carries social meaning (Culpeper and Mclntyre, 2005). Probing how characters perceive interpersonal relationships and how they manage the social context is of key importance for the analysis of the fiction, which is associated with the politeness. The main politeness theories refer to principles explaining why the individual conveys the indirect meaning (e.g., Brown and Levinson, 1987; Simpson, 1995; Leech, 1992). It should note that though adopting politeness strategies maintains social harmony, it does not contribute much to an exciting plot or aid in presenting the dynamic characterization. On the contrary, lessimpoliteness or even impolite conversation behaviors often indicate the tensions between characters, which readers are likely to see developments in both characters and plots.

Under normal circumstances, one would expect a pleasant and felicitous father-and-daughter conversation. To be specific, phatic communication is supposed to be used in the interaction (Simpson, 1989a). According to Fowler (1981), phatic expressions serve the communicative and social function of creating a friendly atmosphere to carry out the following conversation smoothly, which normally happens in the beginning or at the end of a conversation. It is interesting to note that there is no phatic opening in the extract. The father begins the conversation with a direct interrogation (see sentence 2). Normally, phatic expressions in a conversation aim to diminish the tension between interlocutors during the negotiation (Simpson, 1995). However, with no casual talk and begins a conversation with a direct questioning in the father-and-daughter conversation, readers may possibly sense the embarrassment and tense relationship between the Kambili and her father at the very beginning of the novel.

Father acts rude in the entire conversation as he humiliates his daughter by asking a meaningless obvious question (see sentences 24 and 43). Here, the father performs a direct face-threatening act by using a bald on record strategy (i.e., employing the face-threatening act in the most direct and concise manner) (Culpeper, 2001, p.243), which deeply embarrasses Kambili in public. When confronted with the endless face-threatening acts, though the narrator (Kambili) holds an opposite view, she appears to be obedient and uses mitigating ways to redress the impingement upon the father's negative face (see sentences 25 and 39). Instead of giving a direct response to her father, she forces herself to make an unpredictable commitment.

It is interesting to spot that Kambili once tries to go against her father (see sentence 29). Her silent resistance of not reacting to the father's direct command makes him repeat the command (sentence 27). However, her resistance is performed in a rather mitigating manner (i.e., a quiet staring) concerning she has no dare to express her will directly to challenge the father's absolute power.

It can be concluded that the two main characters (the father and the daughter) apply different linguistic strategies regarding the face-threatening issues. The father attacks upon his daughter's face directly (bald on record strategy) and performs threatening acts in a more blatant way. Whereas, Kambili manipulates a mitigating strategy to avoid damaging the father's negative face.

\subsection{Co-operation}

Co-operation makes up a presupposition (here we refer to a general assumption that conversation will be cooperative in Grice's maxims of relation, quantity, quality or manner, which is not equals to the logical and pragmatic presupposition between interlocutors in the interaction), which serves for the successful communication (Leech and Short, 1981). To be precise, it is through the flouting of maxims (the utterance in exchanging information is not socially cooperative), the listeners infer the extra implicit meanings (i.e., implicatures) to ensure the success of the interaction (Leech and Short, 1981).

Kambili' behaviour in the sentence (29) clearly hints that she is unwilling to continue the topic and would rather reject the father's command. Moreover, she breaks the maxim of relation in the sentence (35). Both two examples implicate the attempts the daughter made to avoid the impending and undesirable embarrassment situation that the father is about to make. They also reveal the girl's resistance and a struggle for the dominance of the power (although failure) in order to save her face in the public.

Kambili (the narrator) appears to be obedient and tries to escape from the awkward situation of the father's direct interrogation, who, nevertheless, triggers the endless blame in the following conversation. The father violates the maxim of relation in sentences (24), (34) and (43) by interrogating his daughter with the irrelevant and meaningless 
question. He also breaks the maxim of quantity in the sentence (34) by repeating the truth about one only has one head. By flouting the maxims blatantly, readers can easily access the extra implicatures the father tries to convey. Here, the father has no concern about the number, but show his ironic attitude and express anger to his daughter. This structural parallelism thus reinforces the impression of the father being a bossy and overbearing figure.

In the sentence (35), Kambili's response to the embarrassing question breaks the maxim of relation. Instead of explaining why she fails to rank the first last-term, the daughter gives an ambiguous answer. The breach of the maxim is deliberate and can be interpreted as an indirect measure Kambili takes to avoid further impingement of father and protect her face in front of schoolmates.

\subsection{Character}

The dialogue is a fictional speech; the extract seems has no intention to create the illusion of daily conversation through normal non-fluency (e.g., pauses or interruptions) (Leech and Short, 1981). Nearly all the sentences are presented syntactically perfect, which lead the whole dialogue less-realistic (rarely happens in the normal world). Rather, its perfection is of great expressive value regarding it may bring insights into interlocutors' character and inform readers that the entire conversation is certainly not spontaneous (Culpeper, 2009).

Both father and daughter may possibly know the conversation forthcoming. On the one hand, though not fully assure, Kambili may possibly foresee what will happen in school given the fact that she does not get a satisfactory grade in the last term and father decides to take her to school on the first day of the new semester. Moreover, she has long been under the terror and control of her father, which means she knows the personalities of the father well, especially the consequences of letting him down. In that case, she may sense that she will suffer an uncomfortable experience in the public, which explain why she tries not to offend father's negative face in hope of escaping from the embarrassing situation in front of her schoolmates. The father, on the other hand, is the one who controls the entire conversation. He knows in advance the topic for the conversation and he must have planned words already. All these may present readers with a well-performed father-and-daughter conversation and made readers feel these were the "actual worlds" (Eco,1979; Maitre,1983).

The father is the one who owns dominant power and therefore deserves to be treated with respect. The daughter, thus, avoids displaying face-threatening acts to her father and tries not to offend his negative face (see sentences 25,35 and 39). This thoughtful concern of not challenging the father's face (or not dare to do so) may give readers access to the fear and anxiety of Kambili towards her father. Comparing to the daughter, the father is shaped to be a tyrannical impression since he humiliates her daughter in public with a bald-on record strategy (sentence 34).

\section{Alternative worlds: Plot Development}

The idea that the actual world surrounding by several possible worlds was originally developed by logicians and then modified to apply to the analysis of fiction. This approach has proved to be an important approach which advance the development typologies of the fiction and the study of plot as well as the internal structure of fictional worlds (Semino, 2006). According to Ryan (1991), the fictional texts serves as the universe projecting a complex scenario where one world functions the actual world, and others count as alternative possible states of the actual worlds. These alternative worlds normally related to the characters' desires, goals, obligations, or fantasies (Semino, 2006). Ryan (1991) accordingly distinguished four types of alternative possible worlds: knowledge worlds (i.e., what a character knows about the world where he/she inhabits); obligation worlds (i.e., a character's awareness of his or her moral obligations); wish worlds (i.e., what a character regard as desirable or not); and fantasy worlds (i.e., a character's dreams and fantasies). The classification thus offers us insights into the fiction.

As pointed out by Doležel $(1976,1998)$, it is possible for readers to distinguish between stories that of varied modal-systems and different types of alternative worlds. A state of equilibrium may be achieved when there is a perfect correspondence between characters' alternative worlds and the actual world, which may fail to bring further actions and changes to move forward the plot. In order to start a plot, conflicts between the worlds in a particular narrative universe may concerns important (Ryan 1991). According to Ryan (1991), the conflict may generate between the private worlds of characters in the actual world or between the private worlds of different characters.

In the extract, the father has no attention ever tries to establish a wish world in relation to her daughter, but only an obligation world concerning simply offering the girl the sheltered privilege (mostly material assistance). In reward of this, the father impose his belief of in pursuit of perfection for every aspect of his family's life. The plot of the extract thus sets in motion by the fact - Kambili threatens the wish world of the father at the very beginning concerning she does not rank the first last term - which conflicts with the wish world and the knowledge world of 
the father. The father also threatens Kambili's wish world several times. The daughter wishes to save the face in front of the public. She wants to escape herself from the acutely embarrassing interrogation by avoiding impingement of the father (see sentences 23,35-36, 38-39). However, the father uses the face-threatening language in the conversation, and certainly bring her into an awkward situation in the public.

The incompatible wish world (Ryan, 1991) between the two characters is identified in the extract. Kambili wishes to fully prepared for the father's forthcoming conversation to placate the father and prevent herself from being humiliated in the public, which is stated verbatim in sentences (4) and (18). However, she still undergoes the acutely embarrassing father-and-daughter conversation in front of schoolmates, which conflicts her previous wish world and further move forward the plot. In addition, kambili's wish world collides with the father's wish world (though not explicitly stated in the extract). Kambili wants to maintain a positive image and not publicly being scolded. In order to fulfil her wish world, Kambili switches the topic (see sentence 35) and shows her obedience towards the father (see sentences 38-39), which is counterproductive with father's wishes as his primary purpose is to compel his daughter be aware of the serious consequences of letting him down through the public carry-out conversation in the full view of his daughter's schoolmates. The incompatible wish world thus brings about the need for the actions and changes and contributes to moving forwards the plot.

According to Ryan (1991), self-contradiction is defined as a kind of semantic opposition where the character's wish world collides with one's own actions. This notion has been proved to be a useful approach presenting the irony, which contributes to the high-quality "tellability" (i.e., successfully account for the plot development) and enhances the foregrounding effect in the story (Ryan, 1991; Semino, 2006; 2008). We identify the selfcontradiction in the extract. When confronted with the severe interrogations of the father, the daughter has no intention to answer the questions and is reluctant to continue the topic but rather placate the father and in hope of end the awkward situation as soon as possible. Contradicting with her wish world, the girl shows her obedience and submission, answers the questions one by one, and maintain a low profile towards fathers' endless preach and scold (see sentences 38-39).

Furthermore, the conflict can be seen from the differences in the knowledge worlds of the father and daughter. Father holds a severe catholic belief of "gods expecting perfection" (sentence 37), is zero-tolerant of mistakes, and imposes a harsh religious regime to the households. As a religious zealot and control-freak, he strongly believes that Kambili should work hard as the reward for the "given privileges". On the contrary, Kambili owns an entire different knowledge world, which is stated in verbatim in sentences (29) and (38-39). She is portrayed as a new generation born in the postcolonial Nigerian, by which means her grown-up environment is in sharp contrast to the father. Unlike the father who sticking to the "old-fashioned" thinking, Kambili values and embraces the diversity. Therefore, such conflict between the father-and-daughter knowledge world may further advance the plot and add eminence to the story.

\section{Conclusions}

The goal of this study is to show how a detailed stylistic analysis can reveal the subtle ways in which the different linguistics features can be manipulated to achieve a wide range of significant effects, and present some linguistic evidence to bring insights into claims about the characters and the undercurrents of their interaction. Linguistics aspects which salient in the construction of meaning and frameworks fruitful in the discussion of the individual extract based on a close reading of the literature are employed for approaching the stylistic analysis.

This study examines, in particular, the linguistic control of viewpoint, mind style and speech and thought presentation throughout the extract, which give insights into the narrator's external perception of the particular event in the fictional world. Furthermore, we pay close attention to the interpersonal function of language in the analysis of the conversational part of the extract. Methods of discourse analysis in terms of body language, turntaking mechanism, co-operation, politeness and the character are applied to probe the linguistic strategies and patterns indicated in the dialogue. Findings further demonstrate the characteristics of two main characters, their tense relationship, and the characters' struggle for the dominance of power through the ways they use language in the interaction. In addition, The alternative world is applied to further probe the clashes between the different worlds of the characters, plot development and the internal structure of fictional worlds. Through the interaction with the text's language, the stylistic analysis intends to contribute to a more concrete interpretation of the meaning and the effects that the extract may have upon its potential readers.

It should note that the analysis of individual texts inevitably involves comparisons with others. Also, choices of particular linguistic features and patterns are of great importance since they may be considered deviant, conventional, or typical for different authors, genres or in general language use. Analysts, therefore, are normally 
required to rely on their intuitions as literature readers and hypothesize that institutions will be shared by their audience. The increased availability of corpora may possibly complement analysts' intuitions and strengthen the conclusions drawn from the stylistic analysis of individual texts. In this regard, future studies can be carried out against the background of a relevant corpus.

\section{Funding}

This study was supported by the MOE Project 2019 Vocational Education Teaching and Research (Project No. FLE0001) and the MOE Project of Humanities and Social Sciences (Project No. 20YJA740031).

\section{References}

Adichie, C. N. (2012). Purple hibiscus: a novel. Algonquin Books.

Bockting, I. (1995). Character and Personality in the Novels of William Faulkner: A Study in Psychostylistics. Amsterdam: University of Amsterdam Press.

Broe, V. (2003). Skip-connecting as a means for maintaining coherence - an aspect of the sequential organisation of talk. Acta Linguistica Hafniensia, 35(1), 160-185.

Brown, P. \& Levinson, S. C. (1987). Politeness: Some Universals in Language Usage. Cambridge: Cambridge University Press.

Culpeper, J. (2001). Language and Characterisation. People in plays and other texts. London: Longman.

Culpeper, J. (2009). Reflections on a cognitive stylistics approach to characterization. In J. Vandaele and G. Brone (Eds.), Cognitive Poetics, Goals, Gains and Gaps, Berlin: Mouton de Gruyter.

Culpeper, J., \& McIntyre, D. (2005). Drama: Stylistic Aspects. In Encyclopedia of Language \& Linguistics (pp. 772-786). Elsevier Ltd.

Doležel, L. (1976). Narrative modalities. Journal of Literary Semantics 5, 5-14.

Doležel, L. (1998). Heterocosmica: Fiction and Possible Worlds. Baltimore and London: The John Hopkins University Press.

Eco, U. (1979). The Role of the Reader. London: Hutchinson.

Fludernik, M. (2003). The fictions of language and the languages of fiction. London: Routledge.

Fowler, R. (1977). Linguistics and the Novel. London: Methuen.

Fowler, R. (1981). Literature as Social Discourse. London: Bastsford.

Fowler, R. (1986). Linguistic Criticism. Oxford: Oxford University Press.

Fowler, R. (1996) Linguistic Criticism ( $2^{\text {nd }}$ ed.). Oxford: Oxford University Press.

Grice, H. P. (1975). Logic and conversation. In Cole, P. \& Morgan, J. (Eds.), Syntax and Semantics (pp.4158). New York: Academic Press.

Halliday, M., Matthiessen, C. M., \& Matthiessen, C. (2014). An introduction to functional grammar. London: Routledge.

Lakoff, G., \& Turner, M. (2009). More than cool reason: A field guide to poetic metaphor. University of Chicago Press.

Leech, G. N. \& Short, M. (1981). Style in Fiction. London: Longman.

Leech G. N. (1992). 'Pragmatic principles in Shaw's You Never Can Tell.' In Toolan M (ed.) Language, text and context (pp.259-278). London: Routledge.

Leech, G. N. \& Short, M. (2007). Style in Fiction. London: Longman.

Maitre, D. (1983). Literature and Possible Worlds. London: Middlesex Polytechnic Press.

Ryan, M. L. (1991). Possible worlds, artificial intelligence and narrative theory, Bloomington: Indiana University Press.

Semino, E., \& Swindlehurst, K. (1996). Metaphor and mind style in Ken Kesey's One Flew Over the Cuckoo's Nest. Style, 30(1), 143-166.

Semino, E. (2004). Representing characters' speech and thought in narrative fiction: A study of England, England by Julian Barnes. Style, 38(4), 428-451.

Semino, E. (2006). Possible worlds: Stylistic applications. In Encyclopaedia of Language and Linguistics, $\left(2^{\text {nd }}\right.$ ed. ). Oxford: Elsevier.

Semino, E. (2008). Metaphor in discourse. Cambridge: Cambridge University Press.

Semino, E., \& Short, M. (2004). Corpus stylistics: Speech, writing and thought presentation in a corpus of English writing. London: Routledge.

Short, M. (1996) Exploring the Language of Poems, Plays and Prose. London: Longman. 
Short, M., Semino, E., \& Wynne, M. (2002). Revisiting the notion of faithfulness in discourse presentation using a corpus approach. Language and Literature, 11(4), 325-355.

Simpson, P. (1989a) "Phatic communion and fictional dialogue" in R. Carter and Simpson, P. (Eds), Language, Discourse and Literature (pp. 42-56). London: Routledge.

Simpson, P. (1993). Language, Ideology and Point of View. London: Routledge.

Simpson, P. (1995). Politeness Phenomena in Ionesco's The Lesson. In R. Carter and P. Simpson (Eds.), Language, Discourse and Literature: An Introductory Reader in Discourse Stylistics (pp. 171-194). London: Routledge.

Slembrouck, S. (1992). The parliamentary Hansard 'verbatim'report: the written construction of spoken discourse. Language and literature, 1(2), 101-119.

Toolan, M. (1995) "Discourse style makes viewpoint: The example of Carver's narrator in Cathedral". In P. Verdonk and J.-J. Weber (Eds), Twentieth-Century Fiction: From Text to Context (pp.126-137). London: Routledge.

Toolan, M. (2012). Narrative: A critical linguistic introduction. London: Routledge.

Steen, G. J. (1999). "From linguistic to conceptual metaphor in five steps.” In R. W. Gibbs, Jr. and G. J. Steen (Eds.), Metaphor in Cognitive Linguistics (pp.57-77). Amsterdam: John Benjamins.

Tannen, D. (2007). Talking voices: Repetition, dialogue, and imagery in conversational discourse. Cambridge: Cambridge University Press.

Turner, M. and Fauconnier, G. (2000). "Metaphor, metonymy, and binding." In A. Barcelona (Eds), Metaphor and Metonymy at the Crossroads: A Cognitive perspective (pp.133-145). Berlin: Walter de Gruyter.

Appendix

Modified transcript of the extract from Purple Hibiscus by Chichamanda Ngozi Adichie (2004, pp. 45-48) with numbered sentences below:

(1) Papa finally eased the car into the wide school compound and parked near the volleyball court, beyond the stretch of manicured lawn.

(2) "Where is your class?" he asked.

(3) I pointed to the building by the group of mango trees. Papa came out of the car with me and (4) I wondered what he was doing, why he was here, why he had driven me to school and asked Kevin to take Jaja.

(5) Sister Margaret saw him as he walked to my class. (6) She waved gaily, from the midst of students and a few parents, then quickly waddled over to us. (7) Her words flew generously out of her mouth: (8) how was Papa doing, was he happy with my progress at Daughters of the Immaculate Heart, would he be at the reception for the bishop next week?

(9) Papa changed his accent when he spoke, sounding British, just as he did when he spoke to Father Benedict. (10) He was gracious, in the eager-to-please way that he always assumed with the religious. (11) As gracious as when he presented the check for refurbishing the Daughters of the Immaculate Heart library. (12) He said he had just come to see my class, and Sister Margaret told him to let her know if he needed anything.

(13) "Where is Chinwe Jideze?" Papa asked, (14) when we got to the front of my class. (15) A group of girls stood at the door, talking. (16) I looked around, (17) feeling a weight around my temples. (18) What would Papa do? (19) Chinwe's light-skinned face was at the center of the group, as usual.

(20) "She is the girl in the middle," I said. (21) Was Papa going to talk to her? (22) Yank at her ears for coming first? (23) I wanted the ground to open up and swallow the whole compound.

(24) "Look at her," Papa said. "How many heads does she have?"

(25) "One." (26) I did not need to look at her to know that, but I looked at her, anyway.

(27) Papa pulled a small mirror, the size of a powder compact, from his pocket. (28) "Look in the mirror."

(29) I stared at him.

(30) "Look in the mirror."

(31) I took the mirror, peered at it.

(32) "How many heads do you have, gbo?" Papa asked, speaking Igbo for the first time.

(33) "One."

(34) "The girl has one head, too, she does not have two. So why did you let her come first?"

(35) "It will not happen again, Papa." (36) A light dust Ikuku was blowing, in brown spirals like uncoiling springs, and I could taste the sand that settled on my lips.

(37) "Why do you think I work so hard to give you and Jaja the best? You have to do something with all these privileges. Because God has given you much, he expects much from you. He expects perfection. I did not have a father who sent me to the best schools. My father spent his time worshiping gods of wood and stone. I would be nothing today but for the priests and sisters at the mission. I was a houseboy for the parish priest for two years. Yes, a houseboy. Nobody dropped me off at school. I walked eight miles every day to Nimo until I finished 
elementary school. I was a gardener for the priests while I attended St. Gregory's Secondary School.'

(38) I had heard this all before, how hard he had worked, how much the missionary Reverend Sisters and priests had taught him, things he would never had learned from his idol-worshiping father, my Papa-Nnukwu. (39) But I nodded and looked alert. I hoped my class girls were not wondering why my father and I had chosen to come to school to have a long conversation in front of the classroom building. (40) Finally, Papa stopped talking and took the mirror back.

(41) "Kevin will be here to pick you up," he said.

(42) "Yes, Papa."

(43) "Bye. Read well.” (44) He hugged me, a brief side hug.

(45) "Bye, Papa." (46) I was watching him walk down the path bordered by flowerless green bushes when the assembly bell rang. 